\title{
凋落物分解及其影响机制
}

\author{
贾丙瑞*
}

中国科学院植物研究所植被与环境变化国家重点实验室, 北京 100093

\begin{abstract}
摘 要 为系统了解中国调落物分解及其影响机制的研究进展, 基于当前常用的4个学术期刊数据库(中国知网、ISI Web of Science、ScienceDirect和Springer Link), 检索1986-2018年的相关文献并进行计量分析。中国调落物分解研究以森林生态系统 为主(占65\%), 且多集中于易于观测的地上调落物部分, 未来应加强地下部根系调落物分解研究。调落物分解研究对象通常选 取当地优势种或主要组成物种(约占 $68 \%$ ), 考虑到混合效应的存在, 仅依据单一调落物分解研究结果来反映自然界中混合调 落物的实际分解特征具有局限性。目前中国调落物分解研究主要集中在碳、氮、磷 3 种元素上, 应更多关注影响分解的重要 化学组分(如钾、铁、锰、木质素、单宁等)和环境污染相关重金属元素的迁移转化及调控机理。未来需将植物-调落物-土壤 作为一个整体, 结合生态化学计量学, 系统研究各元素的生物地球化学循环过程、机制及耦合关系。氮沉降和气候变化对调 落物分解的影响是当前研究热点, 特别是氮、磷等多因子交互作用对调落物分解的影响, 以及气候变暖背景下凋落物分解的 温度敏感性、冻土区调落物分解驱动机制的研究。
\end{abstract}

关键词 调落物分解; 中国; 文献计量; 生态化学计量学

贾丙瑞 (2019). 调落物分解及其影响机制. 植物生态学报, 43, 648-657. DOI: 10.17521/cjpe.2019.0097

\section{Litter decomposition and its underlying mechanisms}

JIA Bing-Rui ${ }^{*}$

State Key Laboratory of Vegetation and Environmental Change, Institute of Botany, Chinese Academy of Sciences, Beijing 100093, China

\begin{abstract}
In order to understand the research progress of litter decomposition and its underlying mechanisms, this paper presented a bibliometric analysis of litter decomposition in China from 1986 to 2018 based on the four common literature databases, including CNKI, ISI Web of Science, ScienceDirect and Springer Link. Litter decomposition researches are mainly from forest ecosystems (65\%), and focus on above-ground litter. This suggests that the studies on below-ground litter decomposition should be strengthened in the future. About $68 \%$ studies focused on the litters from dominant species, which couldn't represent the natural decomposition characteristics due to the mixed effects among litters from multiple species. Besides carbon, nitrogen and phosphorus, we should pay more attention to other key chemical components related with decomposition (e.g. K, Fe, Mn, lignin, tannin, etc.) and the heavy metal elements related with environmental pollution. Meanwhile, ecological stoichiometry is an effective method to interlink the biogeochemical cycle in the plant-litter-soil system. Nitrogen deposition and climate change are hot topics in the field of litter decomposition, especially the interactions of multiple factors (e.g. nitrogen, phosphorus, etc.), temperature sensitivity of litter decomposition and underlying mechanisms in permafrost under climate warming context.
\end{abstract}

Key words litter decomposition; China; bibliometrics; ecological stoichiometry

Jia BR (2019). Litter decomposition and its underlying mechanisms. Chinese Journal of Plant Ecology, 43, 648-657. DOI: $10.17521 /$ cjpe. 2019.0097

调落物分解是生态系统养分循环的重要过程, 它将植物中的各种元素释放出来归还土壤, 为植物 根系吸收养分提供来源, 实现了生态系统内部化学
元素的交换。据估计，植物吸收的养分中 $90 \%$ 以上 的氮磷和 $60 \%$ 以上的矿质元素都来自植物归还土壤 的养分再循环(Chapin III et al., 2002)。调落物分解

收稿日期Received: 2019-04-27 接受日期Accepted: 2019-07-10

基金项目: 国家重点研发计划(2017YFC0503906)和公益性行业(气象)科研专项经费项目(GYHY201406034)。Supported by the National Key R\&D Program of China (2017YFC0503906), and the China Special Fund for Meteorological Research in the Public Interest (GYHY201406034).

* E-mail: jiabingrui@ibcas.ac.cn 
是生物地球化学循环过程的关键环节, 在维持生态 系统结构和功能中占据着重要地位。调落物分解包 括: (1)淋溶过程, 调落物中可溶性物质通过水的冲 刷作用而被淋洗掉, 淋溶作用是新近调落物在湿润 环境下质量损失的一个重要过程; (2)粉碎过程, 由 土壤干湿交替、冻融交替、土壤动物及人类活动等 造成的物理破碎; (3)代谢过程, 在微生物及各种酶 作用下把复杂的有机化合物转变为简单的盐类分子 和植物易于吸收的无机化合物(方炜等, 1993; 裴蓓 和高国荣, 2018)。

早在1876年, 德国学者Ebermayer发表了经典 著作《森林调落物产量及其化学组成》, 阐述了调 落物分解在养分循环中的重要性。我国调落物分解 研究起步较晚, 直到 20 世纪 80 年代才开始出现, 然 而近10年来呈快速增长趋势(图1)。本文系统总结调 落物分解研究历程, 基于文献计量分析(截至2018 年)综述我国调落物分解研究进展及存在的主要问 题, 以期为今后调落物分解研究提供参考。

\section{1 研究历程}

表1和表2分别列出了调落物分解研究领域的经 典文献和当前热点文献。

1930年, Melin首次使用碳氮比来分析北美几种 森林凋落物的分解特征, 碳氮比后来成为评价调落 物分解的经典指标。

1943年, Gustafson发现针叶分解过程中形成的 酸性物质抑制了细菌活性, 而阔叶调落物含有大量 的钙能够起到中和作用，从而提高混合调落物的分 解速率; 另外, 高钙含量落叶还能吸引更多的土壤 动物，从而加快分解。

1957年, Bocock和Gilbert在调落物分解研究中 首次使用质地柔软的尼龙网代替坚硬的金属或木质 容器作为分解容器的材料, 即: 分解实验中最经典 且应用最广泛的分解袋法。

1963年, Olson提出负指数衰减模型来描述凋落 物物质残留与分解时间的关系 $\left(M_{\mathrm{t}} / M_{0}=\mathrm{e}^{-k t}\right)$, 式中

表1 调落物分解研究领域经典文献

Table 1 Classical articles in the field of litter decomposition research

\begin{tabular}{lll}
\hline 序号 No. 文献 Reference & 备注 Note \\
\hline 1 & Melin, 1930 & 首次使用碳氮比来分析北美几种森林凋落物的分解特征, 后来成为评价调落物分解的经典指标。 \\
& The carbon:nitrogen ratio was firstly related to litter decomposition in North American forests, and became a common
\end{tabular}

$2 \quad$ Gustafson, 1943 indicator.

针叶分解过程中形成的酸性物质抑制了细菌活性, 而阔叶含有大量的钙能够起到中和作用, 从而提高针阔叶混合 调落物的分解速率。

The needles produced an acid reaction, which would suppress bacterial activity, but the broadleaves with high calcium content could neutralize the decaying material and enhance the decompose rates.

The metal or wooden containers were substituted with nylon mesh bags. Litter-bag method is the most common method for litter decomposition measurement.

$4 \quad$ Olson, 1963

提出负指数衰减模型来描述凋落物物质残留与分解时间的关系, 是凋落物分解过程失重率研究常采用的模型。 Litter mass remaining rate with time was simulated with the negative exponential declining model, which is widely used to describe litter decomposition. Litter decomposition was closely correlated with nitrogen and lignin content, which are still the important research con tents up to now.

用不同孔径分解袋和杀菌处理来区分微生物、土壤动物和非生物因素的贡献, 发现无生物作用的分解速率为 $7 \%$, 只有微生物作用的分解速率为 $15 \%$ ，三者共同作用的分解速率为 $29 \%$ 。

The chemicals and two mesh sizes were used to partition the abiotic, microbial and mesofaunal effects. Litter was decomposed $7 \%$ in the abiotic treatment, $15 \%$ in the microbial treatment, and $29 \%$ in the microbial and mesofaunal treatment.

调落物在分解前期主要受氮限制, 后期为木质素浓度或木质素/氮限制。

As decay proceeded, the main influencing factors were shifted from nitrogen to lignin or lignin:nitrogen ratio.

基于CENTURY模型构建调落物分解模型, 把植物残体分为代谢物质和结构物质。代谢物质易于快速分解, 而结 构物质的分解速率可表达为木质素/纤维素的函数, 比值越高分解越慢。

Litter decomposition was simulated with a revision of CENTURY model. Plant residue was divided into metabolic and structural matter. Metabolic matter is easy to decompose. Structural matter could be expressed with the lignin:cellulose ratio, and the higher the ratio the slower the decomposition rate.

根据酶动力学的基本原理，调落物分解的温度敏感性与调落物碳质量呈负相关关系，即“碳质量-温度”假说。

Based on the theory of enzyme kinetics, the sensitivity of litter decomposition to temperature is negative with its quality, i.e. "carbon quality-temperature" hypothesis.

非加和效应在混合调落物分解质量损失和养分释放中分别占 $67 \%$ 和 $76 \%$ 。

Non-additive effects of mass loss and nutrient release were observed in $67 \%$ and $76 \%$ of tested litter mixtures, respectively. 
表2 调落物分解研究领域当前热点文献

Table 2 Current hot articles in the field of litter decomposition

\begin{tabular}{lll}
\hline 序号 No. 文献 Reference & 备注 Note \\
\hline 1 & Fierer et al., 2005 & $\begin{array}{l}\text { 随着调落物碳质量降低, 调落物分解的温度敏感性逐渐升高, 验证了“碳质量-温度”假说。 } \\
\text { As litter carbon quality declined, litter decomposition became more sensitive to temperature, and the “carbon } \\
\text { quality-temperature” hypothesis was tested. }\end{array}$
\end{tabular}

$2 \quad$ Knorr et al., 2005

氮沉降促进高质量调落物(即低木质素含量)分解，而抑制低质量调落物(即高木质素含量)。

Litter decomposition was stimulated by nitrogen additions for high-quality (low-lignin) litters, but inhibited for low-quality (high-lignin) litters.

$3 \quad$ Austin \& Vivanco, 2006

光降解作用是半干旱区地上调落物分解的主要方式, UV-B和总辐射分别占 $33 \%$ 和 $60 \%$ 。

Litter decomposition in a semi-arid ecosystem was mainly controlled by photodegradation, UV-B and total radiation accounting for $33 \%$ and $60 \%$, respectively.

$4 \quad$ Parton et al., 2007

全球 7 个生物系 21 个地点历经 10 年的调落物分解元素释放试验表明, 叶调落物初始氮含量及其分解剩余量是氮净 释放的主要驱动力(不包括高UV辐射下的干草原)。

A 10-year leaf litter decomposition experiment in 21 sites from seven biomes found that net nitrogen release is mainly driven by the initial nitrogen concentration and mass remaining (not including arid grasslands exposed to high ultraviolet radiation).

$5 \quad$ Cornwell et al., 2008

对六大洲 818 种植物调落物分解研究发现, 物种间基质质量对分解速率的影响远大于气候因素。

The litter decomposition experiments from 818 species on six continents found that the magnitude of species-driven differences is much greater than climate-driven variation.

6 Zhang et al., 2008

凋落物质量可以解释全球调落物分解速率 $70 \%$ 的变动，与纬度和年平均气温结合后解释率提升为 $88 \%$ 。

Total nutrient elements (TN) and $\mathrm{C}: \mathrm{N}$ accounted for $70 \%$ of the variation in the litter decomposition rates. The combination of TN, C:N, latitude and mean annual temperature accounted for $88 \%$ of the variation.

$7 \quad$ Kaspari et al., 2008

磷添加提高叶调落物分解速率 $30 \%$ ，而微量元素添加则提高 $81 \%$, 说明除磷之外还有其他元素可能参与并促进凋 落物的分解。

Leaf litter decomposed 33\% faster with phosphorus $(\mathrm{P})$ addition and $81 \%$ faster with micronutrient additions. Besides $\mathrm{P}$, other micronutrients could also enhance litter decomposition.

$8 \quad$ Coq et al., 2010

对 16 个热带雨林树种研究发现, 虽然调落叶的缩合单宁占调落物干重比例很小 $(<3.7 \%)$, 却能够显著降低调落物 分解速率。

The condensed tannin could significantly decrease litter decomposition rates, though its low concentration $(0-3.7 \%$ dry mass) among 16 tropical rain forest tree species.

$9 \quad$ Manzoni et al., 2010

将调落物分解的化学计量学模型扩展到全球尺度(从北极到热带), 包括磷矿化、有机营养的物理流失和调落物层 的化学异质性。

A stoichiometric model of litter decomposition was extended to global scale (from artic to tropical ecosystems), including phosphorus mineralization, physical losses of organic nutrients, and chemical heterogeneity of litter substrates.

$10 \quad$ Sun et al., 2018 阔叶红松林 35 种木本植物 6 年内叶片分解 $77 \%$, 而根尖仅分解 $35 \%$; 与叶分解调控因素不同，非结构性碳水化合物 及次生代谢产物对细根分解起主导作用，该研究改变了人们以叶分解速率及调控因素来推测根系分解的认识。 Among 35 temperate forest species over six years, the decomposition rates of finest roots $(35 \%)$ were lower than those of leaf litter $(77 \%)$. In contrast to lignin:nitrogen ratio control over leaf decomposition, nonlignin carbon compounds were the main factors for roots. Leaf decomposition patterns are inadequate to describe decomposition of the finest roots.
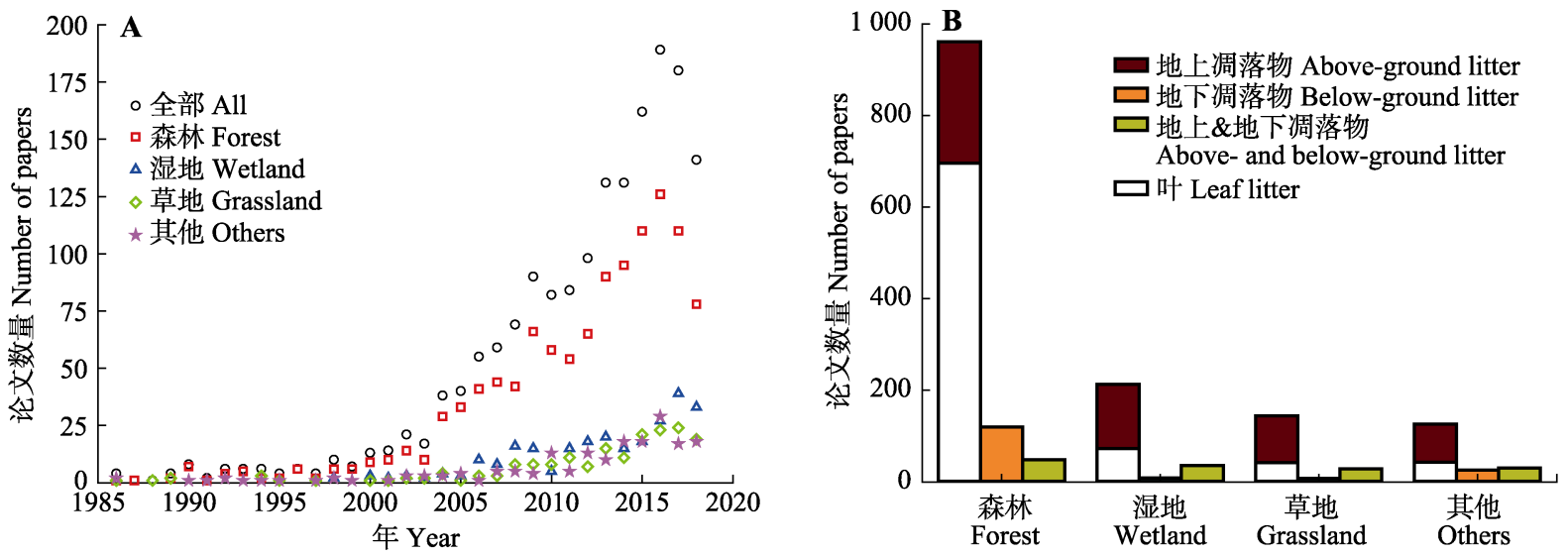

图1 我国不同植被类型调落物分解研究论文数量。A, 1986-2018年年际变动。 $\mathbf{B}$, 不同研究对象论文数量, 包括地上调落物、 地下调落物、地上和地下调落物。白色柱状单指叶片。

Fig. 1 Bibliometric analysis on the litter decomposition in different vegetation types in China. A, Interannual dynamics between 1986 and 2018. B, Classification with research objects, including above-ground, below-ground, above- and below-ground litter. White column represents leaf litter.

$M_{t} / M_{0}$ 为分解 $t$ 时刻调落物残留率(\%), 即调落物在 $t$ 时刻的质量与初始质量的百分比, $t$ 为分解时间, $k$ 为
调落物分解系数, $k$ 值越大表明调落物的分解速度 越快。

www.plant-ecology.com 
1977年, Fogel和Cromack Jr. 提出氮和木质素是 影响调落物分解速率和模式的重要因素, 至今两者 仍是研究的重点。进一步研究发现, 调落物分解前 期主要受氮限制, 后期受木质素浓度或木质素/氮 限制(Taylor et al., 1989)。

1994年, Vitousek等基于CENTURY模型构建调 落物分解模型, 把植物残体分为代谢物质和结构物 质, 前者易于快速分解, 而后者的分解速率可表达 为木质素/纤维素的函数, 比值越高分解越慢。

\section{2 研究进展及存在的主要问题}

选择当前常用的学术期刊数据库(包括中国知 网、ISI Web of Science、ScienceDirect和Springer Link), 中文以“调落物(或枯落物、残落物、叶、根、 枝)”和“分解(或降解、腐解)”为主题词，英文以“litter (leaf, root or branch)” 和 “decomposition (degradation or humification)”为主题词, 截至2018年检 索到我国有关调落物分解的文献共计 1683 篇。我国 凋落物分解的研究最早出现在 20 世纪 80 年代, 2000 年后增长加快, 从每年10余篇论文发表量增加到近 年来每年百余篇(图1A)。按植被类型划分, 我国有 关调落物分解的研究主要集中在森林生态系统, 共 1129 篇(占65\%), 接下来依次为湿地(包括沼泽、河 流、湖泊、滨海等) 258篇、草地181篇、其他(农田、 荒漠、灌从等) 182篇。

\section{1 地上、地下凋落物分解}

目前, 调落物分解研究主要集中于易于观测的 地上调落物部分, 森林、湿地、草地、其他生态系 统分别占 $85 \% 、 83 \% 、 80 \% 、 69 \%$ (图1B)。叶片是森 林地上调落物的主要组成部分, 约占 $70 \%$ (Jia et al., 2018), 在森林生态系统地上调落物分解研究中也 以叶片为主, 约占 $72 \%$ 。应该指出的是, 地下调落物 年输入量在总调落物量中占很大的比重, Freschet等 (2013)估计世界范围内森林和草地生态系统的这个 比值分别是 $48 \%$ 和 $33 \%$ 。大多数研究表明根系调落 物分解速率明显低于叶片调落物(Wang et al., 2010; Freschet et al., 2013; Ma et al., 2016; Liu et al., 2017b; Luo et al., 2017), 而根系调落物氮释放则快于叶片 调落物(Parton et al., 2007), 根系调落物的分解环境 与地上调落物存在很大差异, 两者调控因素各不相 同(Silver \& Miya, 2001; García-Palacios et al., 2016; Jiang et al., 2018), 用影响地上调落物分解的规律来
分析地下调落物分解会造成对生态系统碳循环和养 分循环的错误估计(Freschet et al., 2013; Xia et al., 2015)。Xia等(2018)对美国4种阔叶林的研究发现, 氮添加早期促进了树木凋落叶的分解, 晚期则对细 根分解产生抑制作用。Sun等(2018)对阔叶红松林35 种木本植物 6 年分解研究表明, 大部分叶片被分解 (77\%左右), 而根尖仅分解了 $35 \%$ 左右; 与叶片分解 的调控因素不同，非结构性碳水化合物及次生代谢 产物(酚及单宁酸)对细根分解起着主导作用。另外, 不同树种间细根与叶片调落物分解速率并不相关 (Hobbie et al., 2010)。因而不能以叶片分解速率及其 控制因素来推测根系的分解。目前, 细根分枝系统 中低级根 (直径小于 $0.5 \mathrm{~mm}$ ) 与高级根 (直径0.5-2.0 $\mathrm{mm}$ ) 分解速率的快慢仍存在很大争议(王存国等, 2016)。长期以来，由于技术和方法的限制，作为“黑 箱”的地下生态系统研究成为限制生态学发展的瓶 颈(贺金生等, 2004)。根系的死亡和分解对碳循环和 土壤中养分的有效性具有重要意义, 所以, 未来应 加强地下根系调落物分解研究(如地上与地下整体、 不同径级根系等), 特别是全球变化背景下的影响 调控机制。

\section{2 单一、混合凋落物分解}

陆地生态系统一般是由多物种组成的复杂系统, 在分解过程中不同种类调落物间很可能存在交互作 用。我国已有研究大多集中于单一调落物分解, 共 1151 篇(约占 $68 \%$ ), 混合、单一加混合调落物分解研 究各占约 $16 \%$ (图2)。单一调落物分解研究通常选取 当地优势种或主要组成物种, 在一定程度上代表着 该生态系统的属性。但是, 自然界中调落物通常是 以混合物的形式存在, 仅依据单一凋落物分解研究 结果来反映混合调落物作为一个整体分解的实际特 征具有局限性。为了准确理解调落物的分解过程, 加强混合调落物研究更具有现实意义。

大多数混合调落物分解实验, 通过计算混合调 落物单种组分分解速率与质量比例的加权平均数, 得到混合调落物的期望分解速率, 如果混合调落物 的实际分解速率与期望分解速率相等表现为加和效 应, 混合调落物的实际分解速率偏离于期望分解速 率则表现为非加和效应, 即混合效应(李宜浓等, 2016)。Wardle等(1997)对32个物种叶调落物70个不 同组合分解实验发现，其中45 个表现为正效应，13 个表现为负效应, 12 个表现为加和效应。除了分解速 

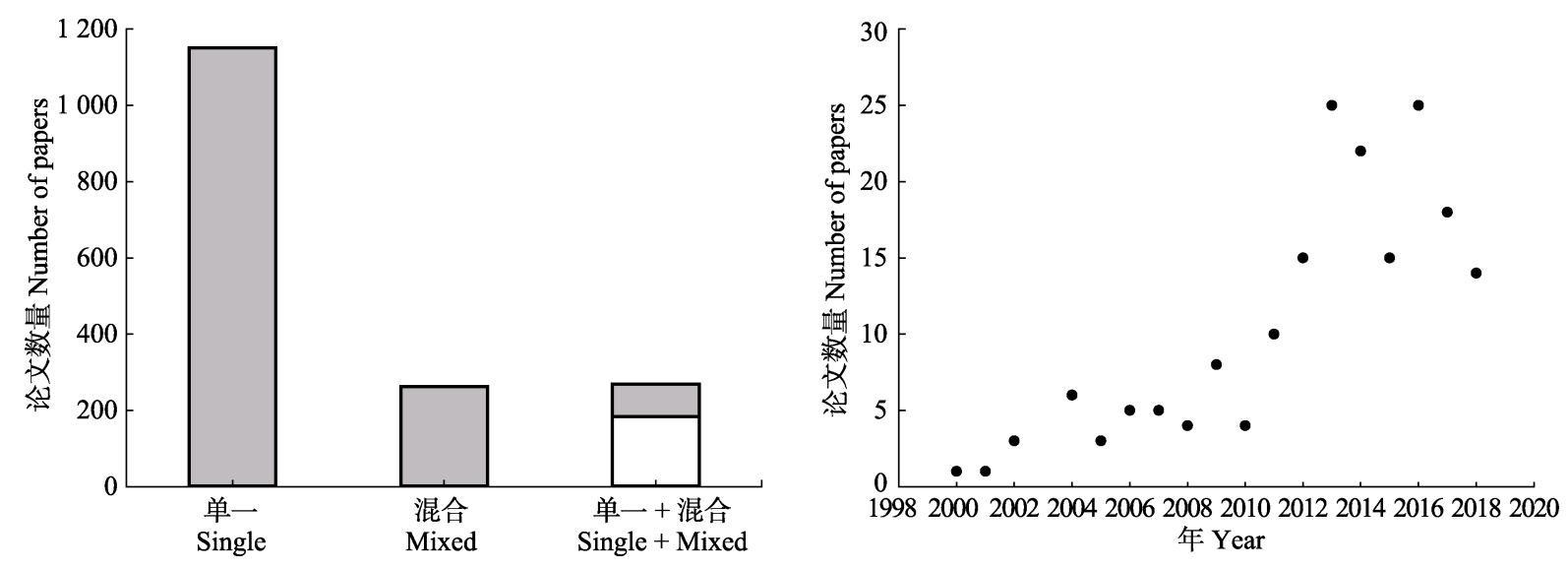

图2 基于单一、混合调落物分解研究的文献计量分析。白色柱状和黑色圆点代表混合效应研究。

Fig. 2 Bibliometric analysis on the single and mixed litter decomposition researches. White column and black dots represent the researches of mixture effects.

率, 调落物混合后还可能影响化学元素的释放动 态。Gartner和Cardon (2004)统计了123个混合调落物 分解元素释放实验，其中 $76 \%$ 的研究表现出显著的 混合效应。国内有关调落物混合效应的研究从 2000 年开始逐渐增多(图2), 关注混合调落物物种组成、 多样性与分解的相互影响机制。调落物混合效应研 究对于农林复合经营模式、人工造林树种选择、外 来入侵种对本地植物分解影响评估等方面具有重要 参考价值。另外要注重长期研究, 因为不同的分解 阶段表现出来的混合效应可能会有所差异, 如 3 种 落叶树混合调落物在分解前 9 个月为正效应, 再经 过 10 个月的分解则表现为负效应(Hansen \& Coleman, 1998)。凋落物混合分解还存在一个难点, 即分 解后期很难区分不同物种的残余物以了解各自的分 解动态, 根的混合分解光其如此。

\section{3 凋落物化学组成}

1958年, Redfield发现海洋浮游生物与海水的碳 $(\mathrm{C})$ : 氮 $(\mathrm{N})$ : 磷 $(\mathrm{P})$ 比值相似, 平均约为 106:16:1 (即 Redfield比率), 这种化学计量学关系反映了生物和 环境之间的紧密联系, 促进了人类对海洋生物地 球化学循环的理解。生态学家也开始在陆地生态 系统探寻是否存在类似的比率模式和相互关系, 进 而诞生了“生态化学计量学”这门新的学科, 着眼于 生态系统中多种化学元素平衡的研究, 也被应用于 调落物分解研究(Güsewell \& Gessner, 2009; Manzoni et al., 2010)中。“底物C、N化学计量学”假说认 为, 微生物分解者与底物间存在 $\mathrm{C} 、 \mathrm{~N}$ 化学计量学的 差异, 这种对分解者生理学上的基本约束驱动调落 物分解和养分释放(Hessen et al., 2004; Parton et al.,
2007; 林成芳等, 2017)。目前我国在调落物分解研 究中对C (1 143篇)、N (1 265篇)、P (934篇)这3种元 素进行了大量报道(图3), 但多集中于调落物基质质 量、化学元素释放动态等方面。植物和土壤以调落 物分解为媒介, 通过动态交换达到并维持相对平衡 的 C:N:P化学计量比, 形成“植物-调落物-土壤”连续 系统(Fan et al., 2016), 我国在这方面的研究尚处于 起步阶段(Chen et al., 2018)。未来需要将植物-调落 物-土壤(或水体)作为一个整体, 系统研究各元素的 生物地球化学循环过程、机制及耦合关系。

$\mathrm{C}$ 是构成植物体内干物质的最主要元素, 是细 胞结构及供能物质的主要成分, $\mathrm{N}$ 和 $\mathrm{P}$ 是构成蛋白质 和遗传物质的两种重要组成元素, 而其他元素对有 机体和生态系统结构与功能也有重要的影响。例如 钾是限制微生物生殖繁衍的主要因素(Ganjegunte et al., 2005); 湿地土壤酶活性主要受铁浓度的影响 (Wang et al., 2017); 锰是合成木质素降解酶的一个 关键组分, 调落物分解后期与锰浓度密切相关 (Berg et al., 2007; Trum et al., 2015; Whalen et al., 2018; Sun et al., 2019); Kaspari等(2008)对巴拿马热 带森林研究发现, P添加提高叶调落物分解速率 $30 \%$, 而微量元素(如硼、钙、铜、铁、镁、锰、钿、硫、 锌)的添加则提高 $81 \%$, 表明除P之外这些微量元素 参与并促进调落物的分解。微生物分解者的生长具 有严格的化学计量特征, 可能某种养分有效性的缺 乏会限制调落物分解(林成芳等, 2017)。另外，木质 素被认为是调落物中较难分解的部分, 其含量是决 定调落物分解快慢的重要因素(Fogel \& Cromack Jr., 1977; Meentemeyer, 1978; Melillo et al., 1982; Taylor

www.plant-ecology.com 
et al., 1989), 单宁也与调落物分解密切相关(Coq et al., 2010; Sun et al., 2018)。目前我国调落物分解研 究中关注的化学元素主要集中在C、N、P这3种元素 上, 其次为钾 (476篇)、钲(264篇)、镁(250篇), 而对 微量元素(如锰、铁、锌、铜等)则关注较少，在21-106 篇之间(图3)。其他元素少于20篇(如铬、铅、镉、铝、 镍、嗍、录、硅等), 本文未列出。因此未来的生态 化学计量学研究应该将更多的注意力放在这些重要 的化学元素上(邢伟等, 2015)。另外在生态环境污染 治理方面, 需加强重金属元素的迁移转化和关键控 制因素研究, 特别是水生环境下的生物地球化学行 为, 定量化评估重金属污染和潜在生态风险。

\section{4 生物因素}

土壤动物(包括水体底栖动物)、微生物和酶活 性对调落物的分解速率有着重要作用, 调落物分解 的实质是微生物在调落物酶和土壤酶系统作用下的 酶解过程。Vossbrinck等(1979)用不同孔径分解袋和

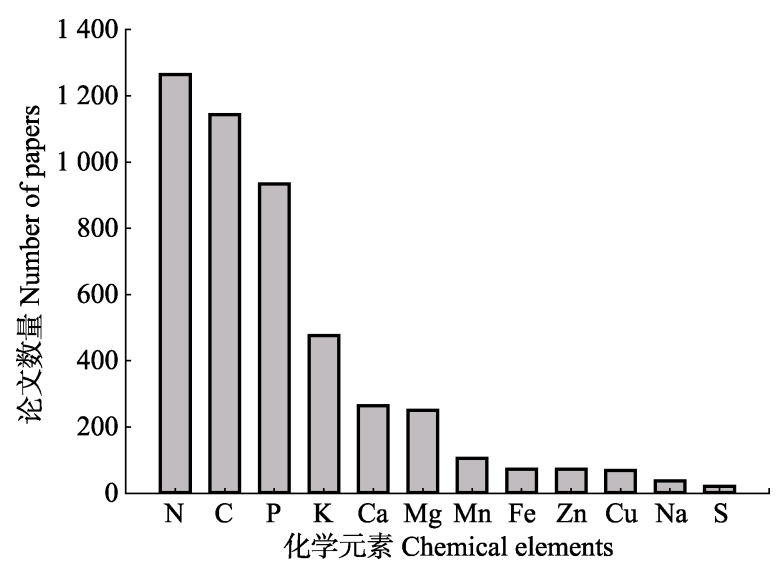

图3 调落物分解研究中化学元素的文献计量分析。

Fig. 3 Bibliometric analysis on the chemical elements of litter decomposition.

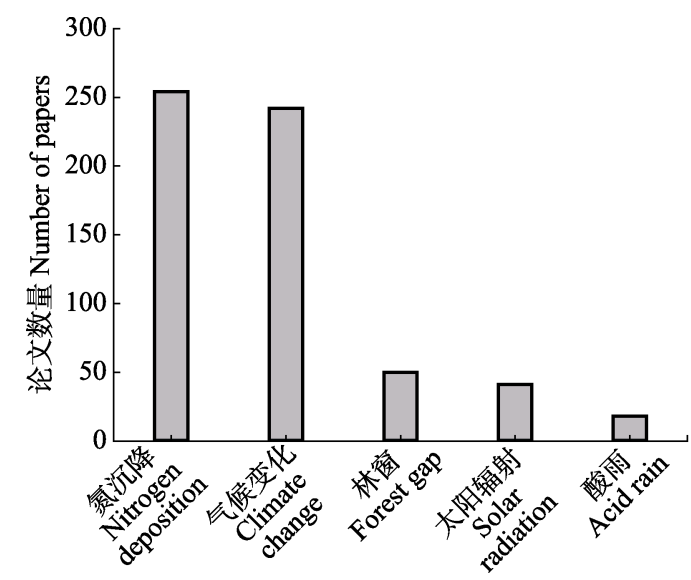

杀菌处理来区分土壤动物、微生物和非生物因素的 贡献，发现无生物作用的分解速率为 $7 \%$ ，只有微生 物作用的分解速率为 $15 \%$ ，三者共同作用的分解速 率为 $29 \%$ 。水生环境下叶分解过程中无脊椎动物占 $51 \%-64 \%$, 真菌占 $15 \%-18 \%$, 细菌占 7\%-9\% (Hieber \& Gessner, 2002)。从已发表的文献来看, 我国对 生物因素的影响研究相对较少, 仅占 $10 \%$ 左右, 近 些年相关研究才逐渐增多(图4), 加强这方面的研究 将有助于人们更深入地理解调落物分解的内在机 制。另外, 以海拔梯度研究气候变化对调落物分解 的影响时, 应全面考虑随着海拔高度变化土壤动物 (Yin et al., 2017)、微生物(金裕华, 2012; Xu et al., 2014)等也发生了改变。

\section{5 全球变化及其他因素}

进入21世纪, 我国科学家在大气 $\mathrm{N}$ 沉降和气候 变化对调落物分解的影响方面开展了大量研究工作, 相关研究文献逐年增多(图5)。大气N沉降是全球变

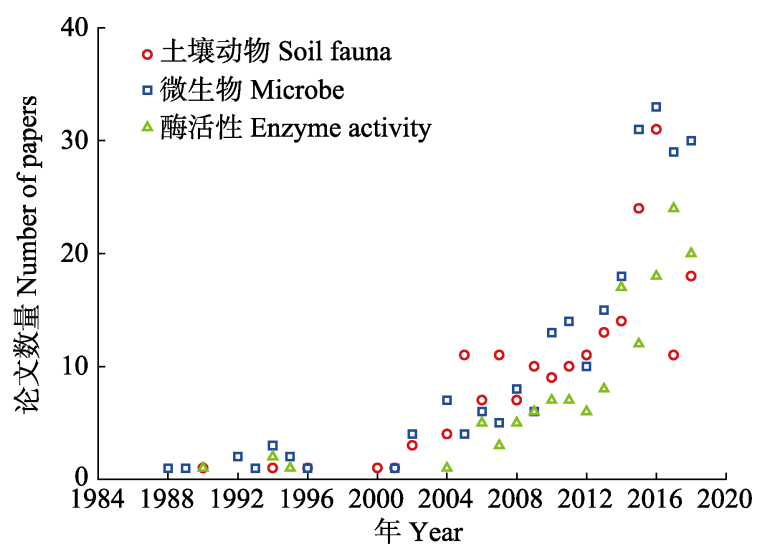

图4 调落物分解研究中生物因素的文献计量分析。

Fig. 4 Bibliometric analysis on the biotic factors of litter decomposition.

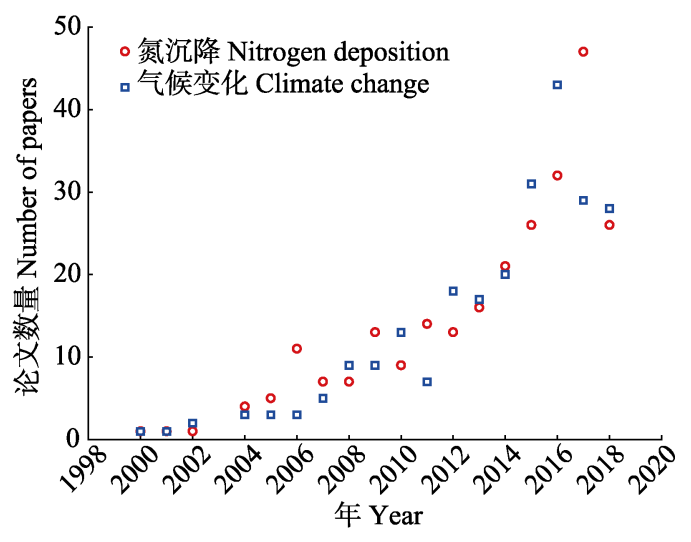

图5 调落物分解研究热点问题的文献计量分析。

Fig. 5 Bibliometric analysis on the research hotspots of litter decomposition. 
化的重要现象, 大气 $\mathrm{N}$ 沉降含有大量植物生长发育 所需的 $\mathrm{N}$, 因而对生态系统的影响受到了格外关注。 $\mathrm{N}$ 输入量增加会引起植物群落结构变化, 导致调落 物质量、土壤理化性质、土壤微生物和土壤动物变 化, 进而影响调落物的分解。长期 $\mathrm{N}$ 添加对调落物分 解酶影响各不相同, 促使纤维素酶活性增强, 而降 低木质素酚氧化酶活性(Carreiro et al., 2000)。因此, $\mathrm{N}$ 沉降促进高质量凋落物(即低木质素含量)分解, 而抑制低质量调落物(即高木质素含量)(Knorr et al., 2005; Janssens et al., 2010)。多年N沉降试验发现, 调落物层土壤节肢动物个体数和类群数随施 $\mathrm{N}$ 浓度 的升高而增加(李曾燕等, 2019)。最新研究表明, 我 国正逐渐由以 $\mathrm{NH}_{4}^{+}$沉降为主的 $\mathrm{N}$ 沉降模式转换为 $\mathrm{NH}_{4}^{+}$和 $\mathrm{NO}_{3}^{-}$并重的新沉降模式(Yu et al., 2019), 未来 应重视N沉降转型变化对调落物分解的影响。N、P 是植物生长最重要的两种限制性养分, 几乎所有生 态系统都存在由于 $\mathrm{N}$ 添加而导致的P限制, 进而影 响调落物的分解过程(Bragazza et al., 2012)。我国有 关 $N$ 、P等多因子交互作用对调落物分解影响的研究 正逐渐增多, 约占N沉降对调落物分解研究的 $22 \%$ 。 同时, 有效体现养分添加效应需要延长观测的时间, 所有调落物全部分解完大约需要3-10年, 而现有的 调落物分解试验大部分少于 2 年(林成芳等, 2017), 短期分解试验结果外推到长时间尺度时需要特别注 意(Moore et al., 2017)。例如少于 2 年的N添加会促进 调落物分解，而 2 年以上则表现为负效应 (Knorr et al., 2005), 未来应加强长期研究。

调落物分解研究中气候变化方面的驱动因子主 要包括增温、降水变化、雪被变化、冻融循环等。 全球气候变化已成为世界关注的焦点, 其中气候变 暖已成不争事实, 尤其在高纬度和高海拔地区 (IPPC, 2014)。根据酶动力学的基本原理, 调落物分 解的温度敏感性与调落物 C质量呈负相关关系, 即 低质量调落物分解需要更高的激活能, 从而对温度 依赖性更强(Bosatta \& Ågren, 1999; Fierer et al., 2005)。然而, Xu等(2012)在青藏高原东部加热试验 发现, 增温明显促进高质量调落物(红桦(Betula albosinensis)) 分解, 而对低质量凋落物(云杉(Picea asperata))没有影响; Liu等(2017a)对亚热带森林生 态系统通过降低海拔模拟升温研究表明, 高质量调 落物(木荷(Schima superba))对增温的响应比低质量 调落物(短序润楠(Machilus breviflora))更强烈。调落
物分解的温度敏感性仍存在很大不确定性, 其内部 调控机制研究有待进一步加强。目前有关我国雪被 变化、冻融循环对凋落物影响的研究共收集到93篇 文献, 90\%以上集中在我国西南部的高山、亚高山生 态系统, 所得结果具有一定的局限性。季节性雪被 格局变化在高纬度地区尤为明显(Aerts et al., 2009), 应加强高纬度冻土区季节性雪被变化、冻融循环对 调落物分解驱动机制的研究。另外, 关注雪被覆盖 期对调落物分解影响的同时, 还应重视无雪期的延 续效应(武启骞和王传宽, 2018)。林窗通过改变林内 水热条件和分解者群落结构而影响调落物分解过程, 我国在这方面也开展了许多研究工作。水分亏缺的 干旱半干旱地区, 光降解作用是凋落物分解的主要 方式(Austin \& Vivanco, 2006); 中国是世界三大酸 雨区之一, 主要分布在长江以南地区且最为严重, 应关注特定环境条件下太阳辐射(特别是UV-B辐 射)、酸雨等对调落物分解的影响, 它们往往会产生 独特的分解特征(Parton et al., 2007)。

\section{3 研究展望}

调落物分解是驱动陆地生态系统 $\mathrm{C}$ 和养分循环 的关键过程, 为全面了解调落物分解过程, 未来应 加强以下几个方面的研究: (1)地下部不同径级根系 调落物分解研究; (2)调落物分解的混合效应; (3)调 落物分解重要化学组分的调控机理; (4) N沉降、气 候变化等多因子交互作用对调落物分解驱动机制的 研究; (5)将植物-调落物-土壤作为一个整体, 结合 生态化学计量学, 系统研究各元素的生物地球化学 循环过程、机制及耦合关系, 特别是与环境污染相 关重金属元素的迁移转化。

\section{参考文献}

Aerts R, Callaghan TV, Dorrepaal E, van Logtestijn RSP, Cornelissen JHC (2009). Seasonal climate manipulations result in species-specific changes in leaf nutrient levels and isotopic composition in a sub-arctic bog. Functional Ecology, 23, 680-688.

Austin AT, Vivanco L (2006). Plant litter decomposition in a semi-arid ecosystem controlled by photodegradation. $\mathrm{Na}$ ture, 442, 555-558.

Berg B, Steffen KT, McClaugherty C (2007). Litter decomposition rate is dependent on litter Mn concentrations. Biogeochemistry, 82, 29-39.

Bocock KL, Gilbert OJW (1957). The disappearance of leaf litter under different woodland conditions. Plant and Soil, 
9, 179-185.

Bosatta E, Ågren GI (1999). Soil organic matter quality interpreted thermodynamically. Soil Biology \& Biochemistry, 31, 1889-1891.

Bragazza L, Buttler A, Habermacher J, Brancaleoni L, Gerdol R, Fritze H, Hanajík P, Laiho R, Johnson D (2012). High nitrogen deposition alters the decomposition of bog plant litter and reduces carbon accumulation. Global Change Biology, 18, 1163-1172.

Carreiro MM, Sinsabaugh RL, Repert DA, Parkhurst DF (2000). Microbial enzyme shifts explain litter decay responses to simulated nitrogen deposition. Ecology, 81, 2359-2365.

Chapin III FS, Matson PA, Vitouseh PM (2002). Principles of Terrestrial Ecosystem Ecology. Springer, New York.

Chen X, Gong L, Liu Y (2018). The ecological stoichiometry and interrelationship between litter and soil under seasonal snowfall in Tianshan Mountain. Ecosphere, 9, e02520. DOI: $10.1002 /$ ecs2.2520.

Coq S, Souquet JM, Meudec E, Cheynier V, Hättenschwiler S (2010). Interspecific variation in leaf litter tannins drives decomposition in a tropical rain forest of French Guiana. Ecology, 91, 2080-2091.

Cornwell WK, Cornelissen JHC, Amatangelo K, Dorrepaal E, Eviner VT, Godoy O, Hobbie SE, Hoorens B, Kurokawa H, Pérez-Harguindeguy N, Quested HM, Santiago LS, Wardle DA, Wright IJ, Aerts R, Allison SD, van Bodegom P, Brovkin V, Chatain A, Callaghan TV, Díaz S, Garnier E, Gurvich DE, Kazakou E, Klein JA, Read J, Reich PB, Soudzilovskaia NA, Vaieretti MV, Westoby M (2008). Plant species traits are the predominant control on litter decomposition rates within biomes worldwide. Ecology Letters, 11, 1065-1071.

Ebermayer E (1876). Die gesammte Lehre der Waldstreu mit Rücksicht auf die chemische Statik des Waldbaues. Unter Zugrundlegung der in den Königl. Staatsforsten Bayerns angestellten Untersuchungen. Springer, Berlin, Heidelberg.

Fan JW, Harris W, Zhong HP (2016). Stoichiometry of leaf nitrogen and phosphorus of grasslands of the Inner Mongolian and Qinghai-Tibet Plateaus in relation to climatic variables and vegetation organization levels. Ecological Research, 31, 821-829.

Fang W, Li MG, Wang BS, Zhang HD (1993). A research of litter leaf in the forest community of Heishiding in Guangdong. Journal of Tropical and Subtropical Botany, 1, 20-30. [方炜, 李鸣光, 王伯䔉, 张宏达 (1993). 广东 黑石顶森林群落调落叶的研究. 热带亚热带植物学报, $1,20-30$.

Fierer N, Craine JM, McLauchlan K, Schimel JP (2005). Litter quality and the temperature sensitivity of decomposition. Ecology, 86, 320-326.
Fogel R, Cromack Jr K (1977). Effect of habitat and substrate quality on Douglas fir litter decomposition in western Oregon. Canadian Journal of Botany, 55, 1632-1640.

Freschet GT, Cornwell WK, Wardle DA, Elumeeva TG, Liu WD, Jackson BG, Onipchenko VG, Soudzilovskaia NA, Tao JP, Cornelissen JHC (2013). Linking litter decomposition of above- and below-ground organs to plant-soil feedbacks worldwide. Journal of Ecology, 101, 943-952.

Ganjegunte GK, Condron LM, Clinton PW, Davis MR (2005). Effects of mixing radiata pine needles and understory litters on decomposition and nutrients release. Biology and Fertility of Soils, 41, 310-319.

García-Palacios P, Prieto I, Ourcival JM, Hättenschwiler S (2016). Disentangling the litter quality and soil microbial contribution to leaf and fine root litter decomposition responses to reduced rainfall. Ecosystems, 19, 490-503.

Gartner TB, Cardon ZG (2004). Decomposition dynamics in mixed-species leaf litter. Oikos, 104, 230-246.

Güsewell S, Gessner MO (2009). N:P ratios influence litter decomposition and colonization by fungi and bacteria in microcosms. Functional Ecology, 23, 211-219.

Gustafson FG (1943). Decomposition of the leaves of some forest trees under field conditions. Plant Physiology, 18, 704-707.

Hansen RA, Coleman DC (1998). Litter complexity and composition are determinants of the diversity and species composition of oribatid mites (Acari:Oribatida) in litterbags. Applied Soil Ecology, 9, 17-23.

He JS, Wang ZQ, Fang JY (2004). Issues and prospects of belowground ecology with special reference to global climate change. Chinese Science Bulletin, 49, 1226-1233. [贺金生，王政权，方精云 (2004). 全球变化下的地下 生态学: 问题与展望. 科学通报, 49, 1226-1233.]

Hessen DO, Ågren GI, Anderson TR, Elser JJ, De Ruiter PC (2004). Carbon sequestration in ecosystems: The role of stoichiometry. Ecology, 85, 1179-1192.

Hieber M, Gessner MO (2002). Contribution of stream detrivores, fungi, and bacteria to leaf breakdown based on biomass estimates. Ecology, 83, 1026-1038.

Hobbie SE, Oleksyn J, Eissenstat DM, Reich PB (2010). Fine root decomposition rates do not mirror those of leaf litter among temperate tree species. Oecologia, 162, 505-513.

IPCC (Intergovernmental Panel on Climate Change)(2014). Climate Change 2014: Mitigation of Climate Change. Cambridge University Press, Cambridge, UK.

Janssens IA, Dieleman W, Luyssaert S, Subke JA, Reichstein M, Ceulemans R, Ciais P, Dolman AJ, Grace J, Matteucci G, Papale D, Piao SL, Schulze ED, Tang J, Law BE (2010). Reduction of forest soil respiration in response to nitrogen deposition. Nature Geoscience, 3, 315-322.

Jia BR, Xu ZZ, Zhou GS, Yin XJ (2018). Statistical characteristics of forest litterfall in China. Science China Life 
Sciences, 61, 358-360.

Jiang L, Kou L, Li SG (2018). Alterations of early-stage decomposition of leaves and absorptive roots by deposition of nitrogen and phosphorus have contrasting mechanisms. Soil Biology \& Biochemistry, 127, 213-222.

Jin YH (2012). Variations of Soil Microbial Diversity Along an Elevation Gradient in the Wuyi Mountains. PhD dissertation, Nanjing Forestry University, Nanjing. [金裕华 (2012). 武夷山不同海拔土壤微生物多样性的变化特征. 博士学位论文, 南京林业大学, 南京.]

Kaspari M, Garcia MN, Harms KE, Santana M, Wright SJ, Yavitt JB (2008). Multiple nutrients limit litterfall and decomposition in a tropical forest. Ecology Letters, 11, 35-43.

Knorr M, Frey SD, Curtis PS (2005). Nitrogen additions and litter decomposition: A meta-analysis. Ecology, 86, 3252-3257.

Li YN, Zhou XM, Zhang NL, Ma KP (2016). The research of mixed litter effects on litter decomposition in terrestrial ecosystems. Acta Ecologica Sinica, 36, 4977-4987. [李宜 浓, 周晓梅, 张乃莉, 马克平 (2016). 陆地生态系统混 合调落物分解研究进展. 生态学报, 36, 4977-4987.]

Li ZY, Qiu XR, Chen GT, Zheng J, Li J, Tu LH (2019). Effects of long-term simulated nitrogen deposition on soil arthropods in a Pleioblastus amarus plantation in rainy area of western China. Chinese Journal of Ecology, 38, 1419-1425. [李曾燕, 邱细容, 陈冠陶, 郑军, 李娟, 涂 利华 (2019). 多年模拟氮沉降对华西雨屏区苦竹人工 林土壤节肢动物的影响. 生态学杂志, 38, 1419-1425.]

Lin CF, Peng JQ, Hong HB, Yang ZJ, Yang YS (2017). Effect of nitrogen and phosphorus availability on forest litter decomposition. Acta Ecologica Sinica, 37, 54-62. [林成芳, 彭建勤, 洪慧滨, 杨智杰, 杨玉盛 (2017). 氮、磷养分有 效性对森林凋落物分解的影响研究进展. 生态学报, 37 , 54-62.]

Liu JX, Liu SG, Li YY, Liu SZ, Yin GC, Huang J, Xu Y, Zhou GY (2017a). Warming effects on the decomposition of two litter species in model subtropical forests. Plant and Soil, 420, 277-287.

Liu X, Xiong YM, Liao BW (2017b). Relative contributions of leaf litter and fine roots to soil organic matter accumulation in mangrove forests. Plant and Soil, 421, 493-503.

Luo D, Cheng RM, Shi ZM, Wang WX (2017). Decomposition of leaves and fine roots in three subtropical plantations in China affected by litter substrate quality and soil microbial community. Forests, 8, 412. DOI: 10.3390/f8110412.

Ma CE, Xiong YM, Li L, Guo DL (2016). Root and leaf decomposition become decoupled over time: Implications for below- and above-ground relationships. Functional Ecology, 30, 1239-1246.

Manzoni S, Trofymow JA, Jackson RB, Porporato A (2010). Stoichiometric controls on carbon, nitrogen, and phosphorus dynamics in decomposing litter. Ecological Monographs, 80, 89-106.

Meentemeyer V (1978). Macroclimate and lignin control of litter decomposition rates. Ecology, 59, 465-472.

Melillo JM, Aber JD, Muratore JF (1982). Nitrogen and lignin control of hardwood leaf litter decomposition dynamics. Ecology, 63, 621-626.

Melin E (1930). Biological decomposition of some types of litter from North American forests. Ecology, 11, 72-101.

Moore TR, Trofymow JA, Prescott CE, Titus BD, the CIDET Working Group (2017). Can short-term litter-bag measurements predict long-term decomposition in northern forests? Plant and Soil, 416, 419-426.

Olson JS (1963). Energy storage and the balance of producers and decomposers in ecological systems. Ecology, 44, 322-331.

Parton W, Silver WL, Burke IC, Grassens L, Harmon ME, Currie WS, King JY, Adair EC, Brandt LA, Hart SC, Fasth B (2007). Global-scale similarities in nitrogen release patterns during long-term decomposition. Science, 315, 361-364.

Pei B, Gao GR (2018). Impact of forest litter decomposition on soil carbon pool: A review. Chinese Agricultural Science Bulletin, 34, 58-64. [裴蓓, 高国荣 (2018). 调落物分解 对森林土壤碳库影响的研究进展. 中国农学通报, 34, 58-64.]

Redfield AC (1958). The biological control of chemical factors in the environment. American Scientist, 46, 205-221.

Silver WL, Miya RK (2001). Global patterns in root decomposition: Comparisons of climate and litter quality effects. Oecologia, 129, 407-419.

Sun T, Cui YL, Berg B, Zhang QQ, Dong LL, Wu ZJ, Zhang LL (2019). A test of manganese effects on decomposition in forest and cropland sites. Soil Biology \& Biochemistry, 129, 178-183.

Sun T, Hobbie SE, Berg B, Zhang HG, Wang QK, Wang ZW, Hättenschwiler S (2018). Contrasting dynamics and trait controls in first-order root compared with leaf litter decomposition. Proceedings of the National Academy of Sciences of the United States of America, 115, 10392-10397.

Taylor BR, Parkinson D, Parsons WFJ (1989). Nitrogen and lignin content as predictors of litter decay rates: A microcosm test. Ecology, 70, 97-104.

Trum F, Titeux H, Ponette Q, Berg B (2015). Influence of manganese on decomposition of common beech (Fagus sylvatica L.) leaf litter during field incubation. Biogeochemistry, 125, 349-358.

Vitousek PM, Turner DR, Parton WJ, Sanford RL (1994). Litter decomposition on the Mauna Loa environmental matrix, Hawai'i: Patterns, mechanisms, and models. Ecology, 75, 418-429.

Vossbrinck CR, Coleman DC, Woolley TA (1979). Abiotic and

www.plant-ecology.com 
biotic factors in litter decomposition in a semiarid grassland. Ecology, 60, 265-271.

Wang CG, Chen ZX, Ma CE, Lin GG, Han SJ (2016). Three potential pathways influencing contrasting decomposition rates of fine roots. Journal of Beijing Forestry University, 38(4), 123-128. [王存国, 陈正侠, 马承恩, 林贵刚, 韩 士杰 (2016). 细根异速分解的 3 个可能影响途径. 北京 林业大学学报, 38(4), 123-128.]

Wang H, Liu SR, Mo JM (2010). Correlation between leaf litter and fine root decomposition among subtropical tree species. Plant and Soil, 335, 289-298.

Wang YY, Wang H, He JS, Feng XJ (2017). Iron-mediated soil carbon response to water-table decline in an alpine wetland. Nature Communications, 8, 15972. DOI: 10.1038/ ncomms 15972.

Wardle DA, Bonner KI, Nicholson KS (1997). Biodiversity and plant litter: Experimental evidence which does not support the view that enhanced species richness improves ecosystem function. Oikos, 79, 247-258.

Whalen ED, Smith RG, Grandy AS, Frey SD (2018). Manganese limitation as a mechanism for reduced decomposition in soils under atmospheric nitrogen deposition. Soil Biology \& Biochemistry, 127, 252-263.

Wu QQ, Wang CK (2018). Dynamics in foliar litter decomposition for Pinus koraiensis and Quercus mongolica in a snow-depth manipulation experiment. Chinese Journal of Plant Ecology, 42, 153-163. [武启寒, 王传宽 (2018). 控雪处理下红松和蒙古栎凋落叶分解动态. 植物生态 学报, 42, 153-163.]

Xia MX, Talhelm AF, Pregitzer KS (2015). Fine roots are the dominant source of recalcitrant plant litter in sugar maple-dominated northern hardwood forests. New Phy- tologist, 208, 715-726.

Xia MX, Talhelm AF, Pregitzer KS (2018). Long-term simulated atmospheric nitrogen deposition alters leaf and fine root decomposition. Ecosystems, 21, 1-14.

Xing W, Wu HP, Shi Q, Liu H, Liu GH (2015). Ecological stoichiometry theory: A review about applications and improvements. Ecological Science, 34, 190-197. [邢伟, 吴 吴平, 史俏, 刘寒, 刘贵华 (2015). 生态化学计量学理 论的应用、完善与扩展. 生态科学, 34, 190-197.]

Xu M, Li XL, Cai XB, Gai JP, Li XL, Christie P, Zhang JL (2014). Soil microbial community structure and activity along a montane elevational gradient on the Tibetan Plateau. European Journal of Soil Biology, 64, 6-14.

Xu ZF, Pu XZ, Yin HJ, Zhao CZ, Liu Q, Wu FZ (2012). Warming effects on the early decomposition of three litter types, Eastern Tibetan Plateau, China. European Journal of Soil Science, 63, 360-367.

Yin X, Qiu L, Jiang Y, Wang Y (2017). Diversity and spatialtemporal distribution of soil macrofauna communities along elevation in the Changbai Mountain, China. Environmental Entomology, 46, 454-459.

Yu GR, Jia YL, He NP, Zhu JX, Chen Z, Wang QF, Piao SL, Liu XJ, He HL, Guo XB, Wen Z, Li P, Ding GA, Goulding $K$ (2019). Stabilization of atmospheric nitrogen deposition in China over the past decade. Nature Geoscience, $12,424-429$.

Zhang DQ, Hui DF, Luo YQ, Zhou GY (2008). Rates of litter decomposition in terrestrial ecosystems: Global patterns and controlling factors. Journal of Plant Ecology, 1, 85-93.

责任编委: 孙建新 责任编辑: 李 敏 实习编辑: 赵 航 